\title{
Embracing Speciality Fertilisers
}

\author{
K.V. Praveen* and K.S. Aditya \\ Division of Agricultural Economics, ICAR-Indian Agricultural Research Institute, \\ New Delhi - 110012, India \\ *Corresponding author
}

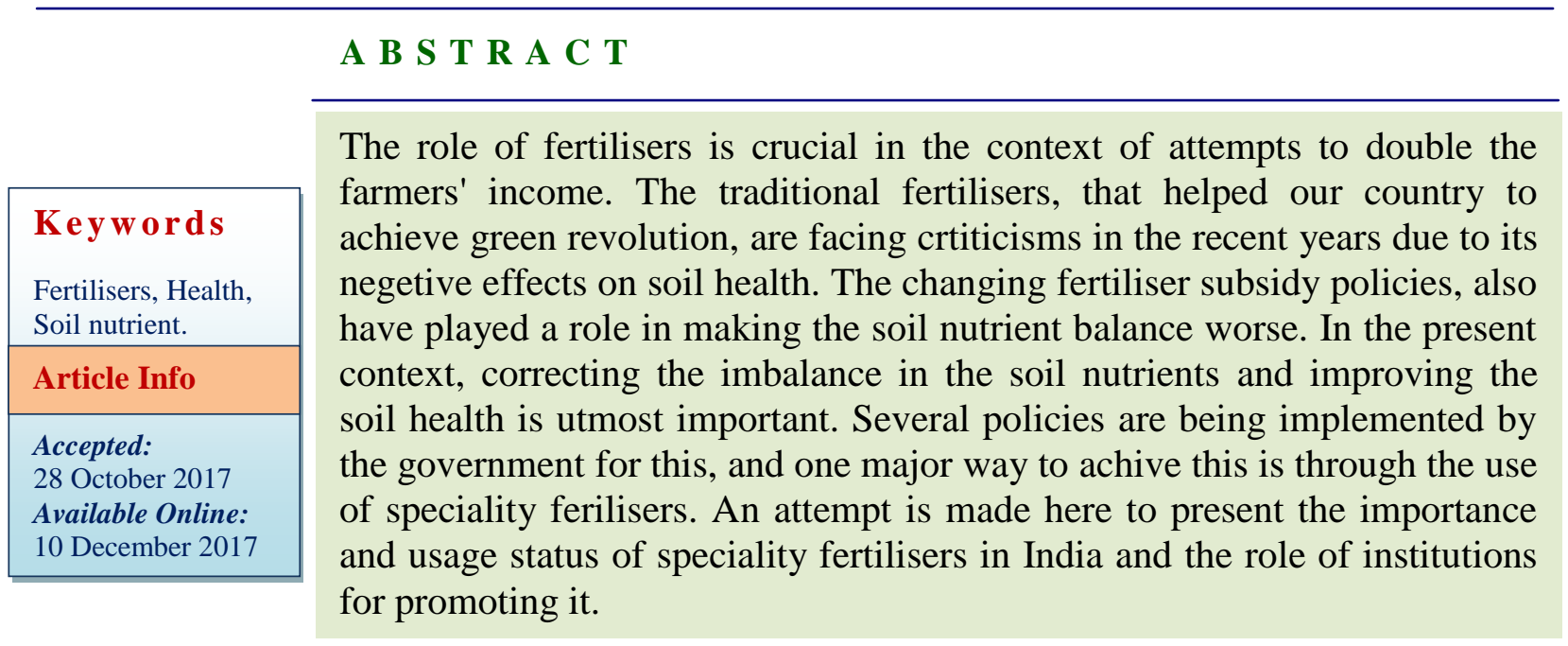

\section{Introduction}

Fertilisers in India still means urea and DAP to a majority. It is true that these traditional fertilisers have played a crucial role, along with technological interventions in the form of high yielding varieties, in yield enhancement during green revolution era and thereafter, but, newer product developments in agricultural input sector should not go unnoticed. More so in the context of India's attempt to double its farmers' income by 2022. The global fertiliser sector has undergone a revolution and a new category of fertiliser generally known as speciality fertilisers have emerged. Speciality fertilisers are those fertiliser products which are applied at special conditions of soil or plant, or to induce special activity in plants. All water soluble fertilisers, slow release fertilisers, Micronutrients and customised fertilisers comes under its ambit.

\section{Speciality fertilisers: Why it is crucial for Indian agriculture}

The importance of speciality fertilisers in the context of Indian agriculture stems from the distorted nutrient ratio in the soils across different agro-climatic regions. Ideally, the NPK ratio of Indian soil should be 4:2:1 but as per the available records, it is around 6.7:3:1. The indiscriminate use of bulk fertilisers, especially the highly subsidized 
nitrogenous fertilisers, without considering the nutrient requirements and soil nutrient status has been reported in case of many crops. Further, nutrient use efficiency is also abysmally low in India more so under rainfed agriculture. Need of the hour is to improve the nutrient use efficiency, promote the use of balanced fertilisers with due importance to secondary and micro nutrients. This report focuses on discussing the status and prospects of speciality fertilisers in India.

\section{Categories of speciality fertilisers}

Understanding the necessity of maintaining the soil nutrient balance, the Government of India has formulated key policies and one among them is to promote the use of speciality fertilisers. The production of the speciality fertilisers in the country have hence, improved to the level of 0.1 lakh tonnes of fortified fertilisers, 0.3 lakh tonnes of water soluble fertilisers and 0.5 lakh tonnes of customised fertilisers as per 2015-16 statistics.

Slow release and fortified/coated fertilisers are the first category of speciality fertilisers, among which neem coated urea is the most popular one in India. Studies have proved that the application of neem coated urea generate significantly higher crop yields and improves the nitrogen use efficiency. Government has taken serious measures to promote this fertiliser by making it mandatory for indigenous urea producers to manufacture 100 per cent of the subsidised urea with coating of neem from May, 2015. At present, 23.1 lakh tonnes of neem coated urea is produced in the country and 22.9 lakh tonnes are sold. Several other fortified/coated fertilisers are also available in the market with different nutrient compositions. Zincated urea, zincated phosphate, NPK complex fertiliser fortified with zinc and born, bentonite sulphur with zinc, DAP fortified with zinc, DAP with born, calcium nitrate with boron, SSP with zinc etc. being the major ones.

Water soluble fertilisers, another category among speciality fertilisers, are at present one of the fastest growing agricultural inputs in the country. They are used for both, fertigation as well as foliar application. Their consumption increased drastically from a meagre 1200 tonnes in the year 1995-96 to 1.7 lakh tonnes in the year 2015-16. Several grades of water soluble fertilisers are available among which calcium nitrate is the most popular one with a share of 25.4 per cent in sales of total water soluble fertilisers, followed by 19-19-19 (19.3\%), potassium nitrate (12.6\%), SOP (9.9\%) and MAP $(9.7 \%)$. The growth in hi-tech farming in the country and the adoption of better irrigation practices like drip and other micro irrigation methods, are the key drivers for increased consumption of these fertilisers in India. Improvement in the fertiliser use efficiency through the use of water soluble fertilisers in fertigation contributes significantly, for example, the nitrogen use efficiency in fertigation is 95 per cent in comparison to 30 50 per cent in soil application. Similarly, the phosphorous and potassium use efficiencies are also higher in fertigation by about 25 and 30 per cent respectively in comparison to soil application. Maharashtra, Karnataka, Andhra Pradesh (undivided), Tamil Nadu and Kerala are the leading consumers of water soluble fertilisers.

Customised fertilisers are yet another category of speciality fertilisers, that targets to embrace site specific nutrient management. Customised fertilisers are in general a combination of nutrients (primary, secondary and micro-nutrients) that are developed as per the requirement of the crop grown and the nutrient status of the soil in a region. At present more than 30 formulations of customised fertilisers are approved for sales 
in India. These formulations are developed, according to regional requirements of soil nutrients, for crops like paddy, wheat, maize, cotton, sugarcane, potato, onion, chilli, apple etc. Total sales of customised fertilisers showed a gradual increase from 0.19 lakh tonnes in the year 2008-09 to 0.45 lakh tonnes in 2015-16 (Fig. 1).

Fig.1 Sales of speciality fertilizers in India ('000 tonnes)

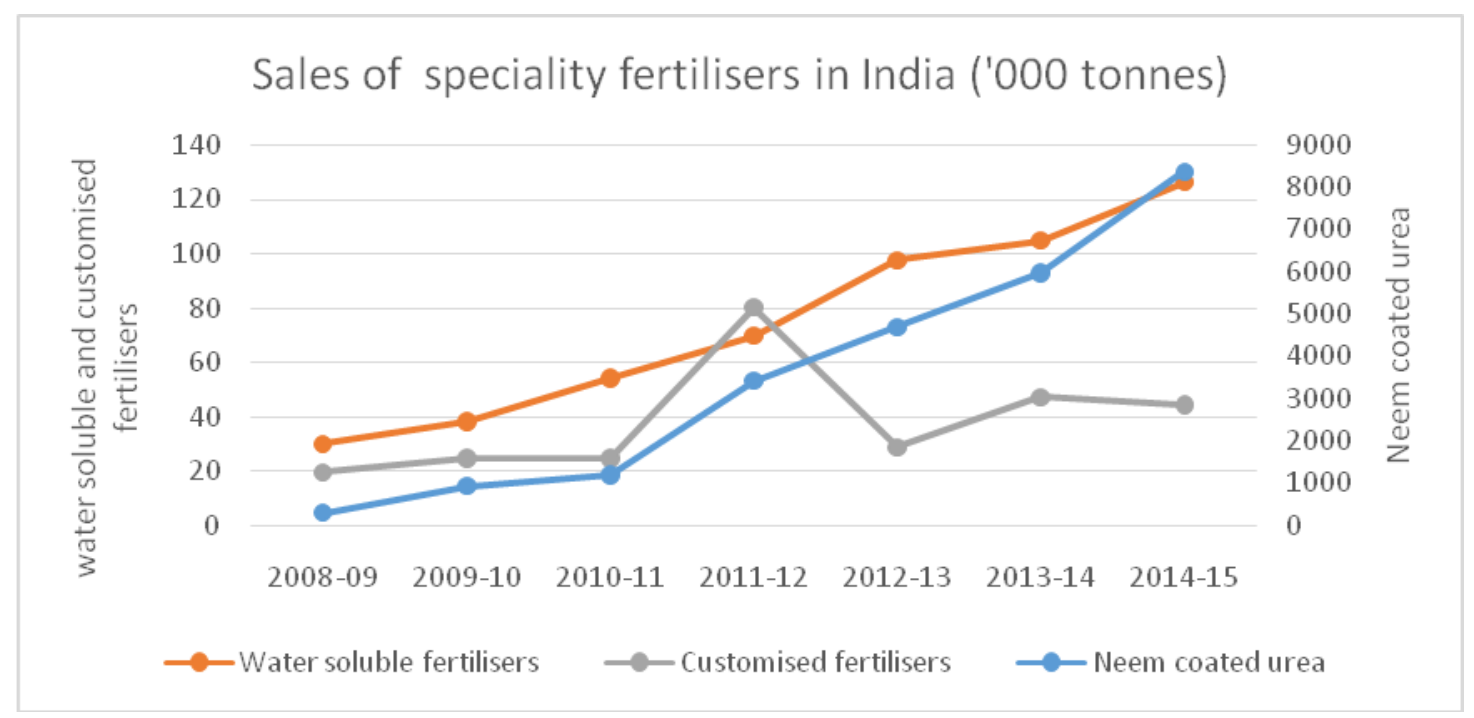

Source: Fertilizer Association of India

Micronutrient and sulphur deficiencies (rather replacement without sufficient replenishment) have probed the industry to develop fertilisers for ensuring their crop specific recommended levels in respective regions. Several of the Indian states are deficient in micronutrients like zinc, copper, iron, manganese, boron and molybdenum. Different specification of micronutrients like zinc sulphate heptahydrate, manganese sulphate, borax, copper sulphate, ferrous sulphate etc. are available in the market, among which zinc sulphate is the highest consumed one (1.8 lakh tonnes), followed by ferrous sulphate (0.2 lakh tonnes) and borax (0.1 lakh tonnes). In addition crop specific micronutrient mixtures are notified by different states. Fertilisers aiming to balance the sulphur content in the soil, for example, Sulphur carrying fertilisers, bentonite sulphur, and magnesium sulphur together constitute a distinct category among speciality fertilisers. Higher level of sulphur deficiency in the soils of eastern, central and north-western states of the country is the answer for the ambiguity in significance of sulphur fertilisers. At present, about 1070 tonnes of sulphur carrying fertilisers, 32629 tonnes of bentonite sulphur and 39003 tonnes of magnesium sulphate are consumed in India. A mention about biofertilisers is also necessary along with the hitherto listed categories if one likes to see a complete picture of Speciality fertilisers. Biofertilisers are the materials that contains living micro-organisms that aids the plants in better nutrient uptake. Rhizobium, azospirillum, azotobacter, blue green algae, azolla and phosphorus solubilising microorganisms are some common biofertilisers available in India. While the application of rhizobium is recommended for pulses, oilseeds and fodders; that of azospirillum and azotobacter are generally suggested for rice, wheat, millets, etc. Blue green algae and azolla are commonly applied in rice fields and phosphorus solubilising 
microorganisms can be used in all crops. The benefits of applying biofertilisers are popularised by the government and this has led to its increased usage (0.08 lakh tonnes in the year 2001-02 to 0.8 lakh tonnes in 2014$15)$.

\section{Role of institutions in promoting speciality fertilisers}

The above discussion will help just to understand the current consumption level of speciality fertilisers in the country. The endeavour should be directed at macro, industry and micro levels. At macro level, policies promoting the usage and awareness of speciality fertilisers should be framed. The extension system of the country has a crucial role to play here in educating the farmers about the importance of adopting these products. Farmers should be provided with exact information regarding the concept, mode of operation, application, extent of soil nutrient enhancement and the yield benefits due to its usage. At the industry level, the fertiliser manufacture industry should be incentivised to focus on better product development in this category. There exist some policies already, that provide permission for indigenous fertiliser producers to manufacture (a prescribed quantity of) Speciality fertilisers and sell these at higher prices (with some exemptions). The burden of such incentives to industry shouldn't however fall on the heads of farmers. Regulations that compels the industry to develop and sell quality Speciality fertilizers of ad hoc nature separately for each crop, region and season (though difficult to implement at one go) at affordable prices for farmers could guide us to surpass the challenge of improving soil nutrient balance. At micro level, soil testing (which currently gained momentum) is to be made compulsory and the results should be provided to the farmers along with a prescription of the nutrient status and Speciality fertiliser products available to be applied there.

Despite the governments' attempt to promote the production and availability of Speciality fertilisers, its consumption is regarded as less in India considering the country's agricultural status. Indian farmers will have to be first brought out of the predicament, they are in, due to heavy dependence on bulk fertilisers, so that they can adopt Speciality fertiliser products. Awareness creation among famers holds the key for this. Ones the farmers start to recognise the potential of these products, the gap between nutrient extraction and replenishment can be bridged better.

\section{References}

Fertiliser Association of India. 2015. Speciality Fertiliser Statistics 2014-15. New Delhi

\section{How to cite this article:}

Praveen, K.V. and Aditya, K.S. 2017. Embracing Speciality Fertilisers. Int.J.Curr.Microbiol.App.Sci. 6(12): 3865-3868. doi: https://doi.org/10.20546/ijcmas.2017.612.446 